\title{
Impact of natural ventilation strategies on IAQ and energy consumption for residential building in Shenyang

\author{
Huifen Zou ${ }^{1, a}$, Xiaozhen $\mathrm{CaO}^{1, \mathrm{~b}}$, Yingchao $\mathrm{Fei}^{1, \mathrm{c}}$, Sheng Ye $\mathrm{e}^{2, \mathrm{~d}}$
}

${ }^{1}$ School of Municipal and Environment Engineering, Shenyang Jianzhu University, Shenyang, Liaoning, China, 110168;

${ }^{2}$ Management School, Shenyang Jianzhu University, Shenyang, Liaoning, China, 110168;

a email: hj_zhf@sjzu.edu.cn, ${ }^{b}$ email: hj_cxz@sizu.edu.cn, ${ }^{c}$ email: feiyingchao@sjzu.edu.cn, ${ }^{\mathrm{d}} \mathrm{email}$ : yeshome325@163.com

Keywords: IAQ; Energy consumption; Air change rate; Carbon dioxide

\begin{abstract}
In order to improve indoor air quality and reduce energy consumption of residential building, the paper focuses on measuring the concentration of $\mathrm{CO}_{2}$ and calculating the air change rate with different ventilation time to evaluate the performance of natural ventilation. Results show that it is difficult to meet the requirement of IAQ when the window is closed, unless open the window at a suitable period. Comparison of the $\mathrm{CO}_{2}$ concentration and indoor air temperature under different conditions shows that the concentration of $\mathrm{CO}_{2}$ is greatly influenced by air change rate.
\end{abstract}

\section{Introduction}

Since 1950s, the proportion of urban architecture energy consumption has continued to increase and reach to $28 \%$ of China's total energy consumption at 2000 . Nearly $68 \%$ of the total energy used in residential building is attributed to HVACs ${ }^{[1]}$. Sealing devices are used to reduce the demand of heating and cooling. It will increase the concentration of indoor contaminants at the same time ${ }^{[2]}$.

Natural ventilation system is the most energy-efficient method in residential building because it uses the totally free resources such as wind and solar energy ${ }^{[3]}$.In natural ventilation system, the air change rate is often used as an important characteristic of the indoor air quality and helps to determine how quickly the polluted air is replaced by fresh. It is indicated that size, shape and placement and other factors of ventilation opening provide a significant influence on IAQ ${ }^{[4-6]}$.

\section{Methodology}

\section{Carbon dioxide}

In this paper $\mathrm{CO}_{2}$ was chosen as the tracer-gas, because it does not cost much and can satisfy accuracy requirements ${ }^{[7]}$. In the residential building, $\mathrm{CO}_{2}$ is mainly produced by people. The $\mathrm{CO}_{2}$ emission rate $\left(F, \mathrm{~cm}^{3} / \mathrm{s}\right)$ is determined by four parameters: height $(\mathrm{H}, \mathrm{m})$, weight $(\mathrm{W}, \mathrm{kg})$, the level of activity $(M$, met $)$ and the respiratory quotient $(R Q, 0.83)$ of people ${ }^{[8]}$. Equation can be written as:

$$
F=R Q \frac{0.00056028 \times H^{0.725} \times W^{0.425} \times M}{(0.23 \times R Q+0.77)} \times 10^{-3}
$$

\section{Air change rate}

In this paper, we calculate the air change rate based on the increase of $\mathrm{CO}_{2}$ concentration between two measurements performed with time interval ${ }^{[9,10]}$.

$$
C=C_{v}+\frac{F}{N}-\left(C_{v}+\frac{F}{N}-C_{o}\right)\left(e^{-\frac{N}{V} \tau}\right)
$$

Where, $N$ is the air change rate $\left(\mathrm{m}^{3} / \mathrm{s}\right), F$ is the $\mathrm{CO}_{2}$ emission rate $\left(\mathrm{cm}^{3} / \mathrm{s}\right), V_{\text {zone }}$ is the volume of the zone $\left(\mathrm{m}^{3}\right), C$ is the concentration of $\mathrm{CO}_{2}$ in room air $(p p m), C_{v}$ is the 
concentration of $\mathrm{CO}_{2}$ in outdoor air $(p p m), C_{0}$ is the initial concentration of $\mathrm{CO}_{2}(p p m), \tau$ is the time.

\section{Experimental conditions}

The experiment carried out from 31 October to 30 November 2011 . The test room is $34 \mathrm{~m}^{3}$.

Experiments under different conditions were conducted in Table 1. During the experiments, the indoor temperatures, relative humidity, concentration of $\mathrm{CO}_{2}$ were recorded. Measurements of indoor and relative humidity were carried every minute using the graphic instrument RR002 at height $1.2 \mathrm{~m}$ at the four different locations. The concentration of $\mathrm{CO}_{2}$ was measured every two minutes at the head of the bed using the hand held Telaire 7001 Monitor.

Table 1 Experimental conditions

\begin{tabular}{|c|c|c|}
\hline Measurement time(h) & Window opening time(h) & Human occupants \\
\hline \multirow{4}{*}{ 19:00-6:00 } & $19: 30$ & 1 \\
\cline { 2 - 3 } & $20: 00$ & 1 \\
\cline { 2 - 3 } & $20: 30$ & 1 \\
\cline { 2 - 3 } & closed & 1 \\
\cline { 2 - 3 } & $20: 00$ & 2 \\
\hline
\end{tabular}

Properly ventilated buildings should have $\mathrm{CO}_{2}$ levels between $600 \mathrm{ppm}$ and $1000 \mathrm{ppm}$, with a floor or building average of $800 \mathrm{ppm}$. Therefore, $1000 \mathrm{ppm}$ used as a sign for closing window.

In order to control the experimental variable, the outdoor air temperature and velocity changed slightly on each comparison task. $\mathrm{CO}_{2}$ produced by one or two people. The physical data of people was given in Table 2. The person entered the bedroom every 19 p.m. and stayed inside until 6 a.m. next morning. Since the $\mathrm{CO}_{2}$ production is major depend on the metabolic rate, the person in the bedroom were asked to sleep or lie in the bed. The metabolic rate corresponds to a tabulated value for a sleeping person $(0.7 \mathrm{met})$.

Table 2 Physical data of people during the experiment

\begin{tabular}{|c|c|c|c|}
\hline & H (m) & W (kg) & M (met) \\
\hline Person A & 1.73 & 65 & 0.7 \\
\hline Person B & 1.60 & 60 & 0.7 \\
\hline
\end{tabular}

\section{Results}

\section{Computed results}

The results of the air change rates in bedroom under different experimental conditions by formula (2) are presented in Table 3.

Table 3 Air change rates in bedroom

\begin{tabular}{|c|c|c|}
\hline Human occupants & Air change rate (L/s) & Window opening time(h) \\
\hline $\mathbf{1}$ & 0.41 & $19: 30$ \\
\hline $\mathbf{1}$ & 0.79 & $20: 00$ \\
\hline $\mathbf{1}$ & 0.58 & $20: 30$ \\
\hline $\mathbf{1}$ & 0.26 & closed \\
\hline $\mathbf{2}$ & 1.59 & $20: 00$ \\
\hline $\mathbf{2}$ & 0.18 & closed \\
\hline
\end{tabular}

\section{Outdoor climatic environment}

During the experiment period, the frequency of outdoor air temperature and relative humidity are given (Fig.1 and Fig.2), respectively. 


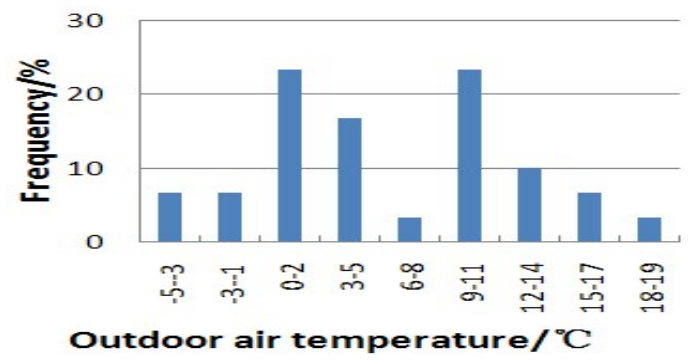

Fig.1 Frequency of outdoor temperature

\section{Change in indoor climatic}

Changes of $\mathrm{CO}_{2}$ concentration, indoor air temperature are presented in Fig.3 and Fig.4. From Fig. 3 we can see that in 1-person bedroom with a closed window the morning $\mathrm{CO}_{2}$ concentration is $3960 \mathrm{ppm}$ exceeded the acceptable long-term exposure range (ALTER) for $\mathrm{CO}_{2}$ in residential indoor $\operatorname{air}(\leq 3500 \mathrm{ppm})^{[11]}$

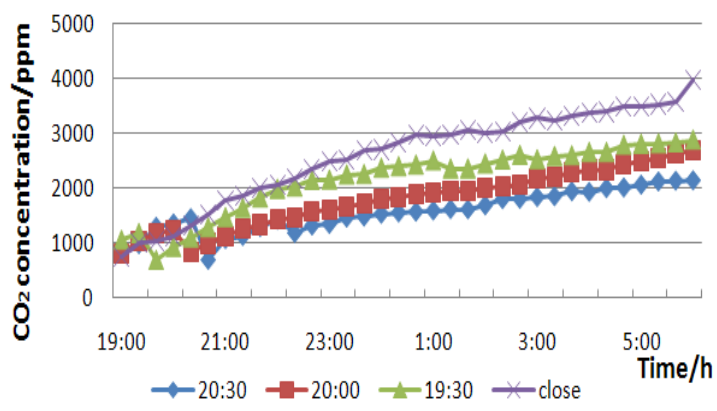

Fig.3 $\mathrm{CO}_{2}$ concentration level in 1-person bedroom with different opening time

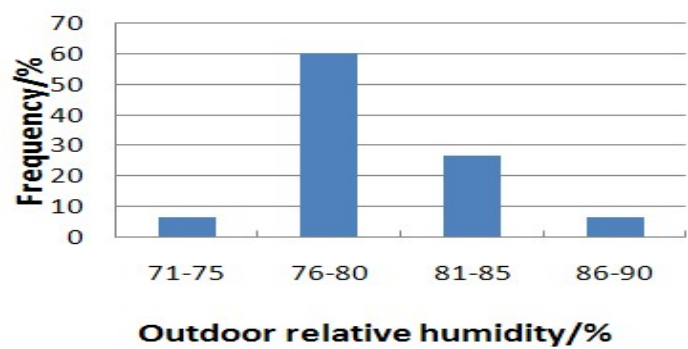

Fig.2 Frequency of outdoor relative humidity

Fig. 4 shows that the minimize decline of indoor air temperature is $0.8^{\circ} \mathrm{C}$ at $20: 00$. Owing to a decrease in air change rate, the morning $\mathrm{CO}_{2}$ concentration in bedroom with closed window is higher than others. Results show that the ventilation performance increases with increasing the air change rate, the indoor air temperature decay are $1.2,1.0,0.8^{\circ} \mathrm{C}$ for air change rate of $0.58,0.41$, $0.79 \mathrm{~L} / \mathrm{s}$, respectively. But the indoor air temperature in bedroom under different conditions investigated changed from 20 to $22^{\circ} \mathrm{C}$, which is acceptable.

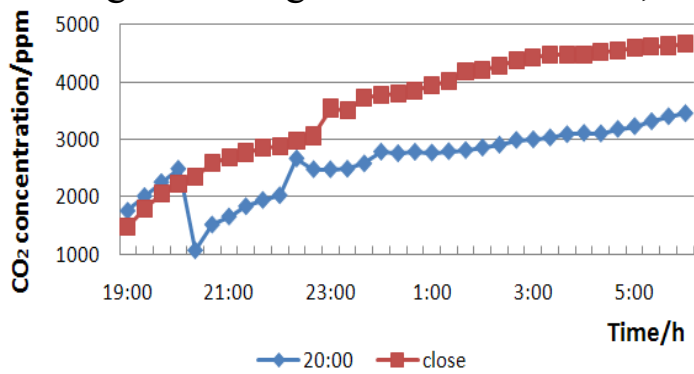

Fig.5 $\mathrm{CO}_{2}$ concentration level in 2-person bedroom with different opening time

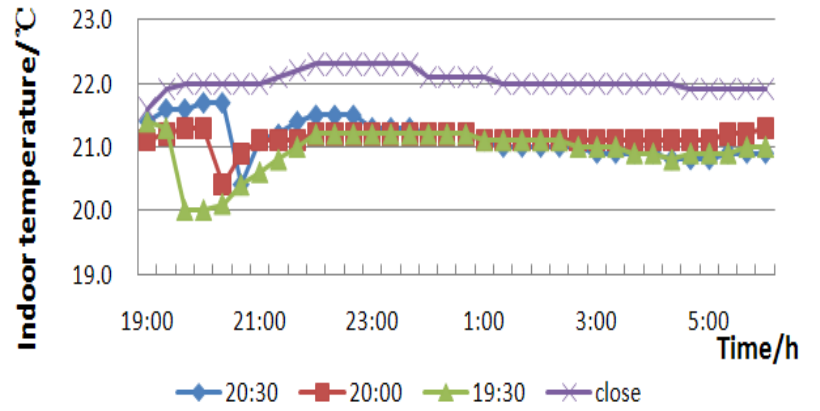

Fig.4 Indoor air temperature in 1-person bedroom with different opening time

Fig. 6 shows that in 2-person bedroom, the morning $\mathrm{CO}_{2}$ concentration is 4660, 3452ppm, respectively. Reach the maximum value of long-term exposure range. From Fig. 3 and Fig. 6 we can see that bedroom with an opened window, the IAQ is better than others. But in all bedrooms the morning $\mathrm{CO}_{2}$ concentration reaches up to 2000ppm.

\section{Conclusions}

1) Investigation shows that the indoor climate of a natural ventilation residential building is greatly influenced by air change rate.

2) The operation of closing the window during nighttime can hardly meet the requirement of IAQ in Shenyang. Even the indoor temperature $20-22^{\circ} \mathrm{C}$ is acceptable, since the fact that the 
window was tightened and people paid a lot of attentions to the envelope elements and the heating aspect.

3) Size, shape and placement of ventilation openings provide a significant optimization potential for air exchange rates and energy consumption, but the investigation proved that a suitable ventilation time is also important for IAQ and energy conversation. The decline of indoor temperature is not all the same under different ventilation times. Changing of ventilation strategies makes it possible to solve the IAQ problems and increase energy efficiency in a residential building.

\section{References}

[1] Ministry of Construction of PRC: Construction Technology Vol. 31 (8) (2002), p.1-6.

[2] F. Chlela, A. Husaunndee, C. Inard, P.Riederer: Energy and Building Vol. 41 (2009), p.982-990.

[3] M.H. Kim, J.H. Hwang: Energy and Buildings Vol. 41 (2009), p. 579-586.

[4] P. Karava, T. Stathopoulos: International Journal of Ventilation Vol. 3 (3) (2004), p. 255-266.

[5] Astrid Roetzel, Aris Tsangrassoulis, Udo Dietrich, Sabine Busching: Renewable and Sustainable Energy Reviews Vol. 14 (2010), p.1001-1013.

[6] C.F. Gao, W.L. Lee: Building and Environment Vol.46 (2011), p. 961-969.

[7] Roulet CA, Foradini F. International Journal of Ventilation Vol. 1(1) (2000), p.39-44.

[8] A.K. Persily, Ph. D.: ASHRAE Transactions Vol. 103 (1997), part2.

[9] T.-A.Koiv, H.Voll, M.Rebane: The International Conference in Sustainable Development in Building and Environment (Chongqing 28-30 October, China 2009)

[10] T.-A.Koiv: Proc. Estonian Acad. Sci. Eng. Vol. 13 (1) (2007), p.17-25.

[11] Environmental Health Directorate: Exposure guidelines for residential indoor air quality: A report of the federal-provincial advisory committee on environmental and occupational health (Canada 1989). 